\title{
Impact of COVID-19 on Food Systems and Rural Livelihoods in Kenya
}

\author{
COVID-19 Country Report - September 2020 Prepared by John Olwande
}

\section{Introduction}

Kenya confirmed its first case of COVID-19 on 12 March 2020. Since then, the government has been providing daily updates on the number of new COVID-19 infections, recoveries and deaths in the country, as well as implementing several interventions to manage the disease. The cumulative numbers as of 12 August 2020 were 27,425 new infections, 13,867 recoveries and 438 deaths, and rising. The objective of this assessment was to understand the effects of COVID-19 on the food system and the sub-set of the population largely dependent on agriculture. The findings were intended to inform actions to assure protection of rural livelihoods and the continued supply of adequate and affordable food of acceptable quality to the population.

\section{Context}

The assessment was conducted through a household survey of a stratified random sample of 100 smallholder agricultural households (29 female-; 71 male-headed) in five counties: Kiambu, Kilifi, Kwale, Muranga and Nakuru, which are in close proximity to Nairobi and Mombasa, the country's initial hotspots for COVID-19 infections. The sample was obtained from the Tegemeo Agricultural Policy Research and Analysis household survey conducted in 2014, which had a total sample size of 7,000 households spread across 38 counties.

\section{Health and disease}

All respondents were aware of COVID-19, but there was no incidence of infection in the households and only $9 \%$ of respondents had heard about a confirmed case in their village or sub-county. Respondents reported increased care for children (58\%), and an increased burden for cooking, cleaning and fuel and/or water collection (42\%). The increase in these responsibilities is not surprising because all learning institutions were closed, and children were mostly at home.

\section{Farm labour and marketing}

Approximately $23-30 \%$ of respondents reported that they or their spouse had decreased participation in farming due to COVID-19. About 58\% were unable to hire labour for their farm and their business activities, but wage rates for daily and seasonal work remained largely unaffected.

\section{"With the COVID-19 outbreak, finding casual} work for small-scale farmers was a challenge as demand for off-farm labour decreased drastically. This has made it difficult for those farmers to get the extra income they need to purchase muchneeded agricultural inputs." - Agricultural Officer, Kilifi County

\section{Key findings}

- All respondents were aware of COVID-19, but there were no reports of infected persons within the villages.

- Over $75 \%$ of respondents observed guidelines for prevention of the spread of COVID-19.

- A sizeable number of respondents reported decreased participation in farming (22\%) and off-farm business (37\%) activities due to COVID-19.

- The ability to access farm gate and local markets to sell produce decreased for $31-47 \%$ of respondents.

- There was reduced availability of farm and off-farm employment opportunities within and outside the villages

- About a third of respondents reported a decrease in the availability of farm inputs, while over half reported that the price of inputs had increased.

- Between $43-58 \%$ of respondents reported decreases in the availability of agricultural extension services, credit and concessionary loans/loan 'holidays'.

- Over $40 \%$ of respondents reported reduced availability of fruits and vegetables, pulses, nuts and seeds, and white roots and tubers in local markets, while over one third observed a decrease in the supply of grains, processed foods and fish and seafood. Over 40\% stated that prices increased for most food items.

- Nearly $90 \%$ of households did not have adequate food and $97 \%$ reported that their cost of living had gone up since the COVID-19 restrictions came into effect.

- Close to $60 \%$ of households had not received any form of assistance to support them during the crisis.

Between $31 \%$ and $47 \%$ of respondents reported a decrease in ability to sell their produce at the farm gate and in local markets, while $88 \%$ reported a decrease in the number of traders/brokers that came to their villages. These statistics indicate restricted access to markets for agricultural produce due to COVID-19.

\section{Availability of services for food production}

A decrease in the availability of key agricultural inputs, such as fertilisers, certified seeds, agrochemicals, and veterinary drugs were reported by $32 \%$ of respondents, while $51 \%$ reported that prices of the inputs increased. 
A substantially high number of respondents also reported a decrease in availability of agricultural extension services (58\%), credit $(52 \%)$ and concessionary loans/loan 'holidays' (43\%). These can potentially hinder farmers' access to adequate agricultural inputs and services, thereby reducing agricultural production in subsequent seasons, with undesirable consequences to the country's food supply and rural livelihoods.

\section{Food and nutrition security}

- Over $40 \%$ of respondents reported reduced availability of fruits and vegetables, pulses, nuts and seeds, and white roots and tubers in local markets.

- About one-third of respondents observed a decrease in the supply of grains, processed foods and fish and seafood.

- Over $40 \%$ reported that prices increased for most food items, especially grains and pulses, nuts and seeds.

- About $89 \%$ of households did not have adequate food.

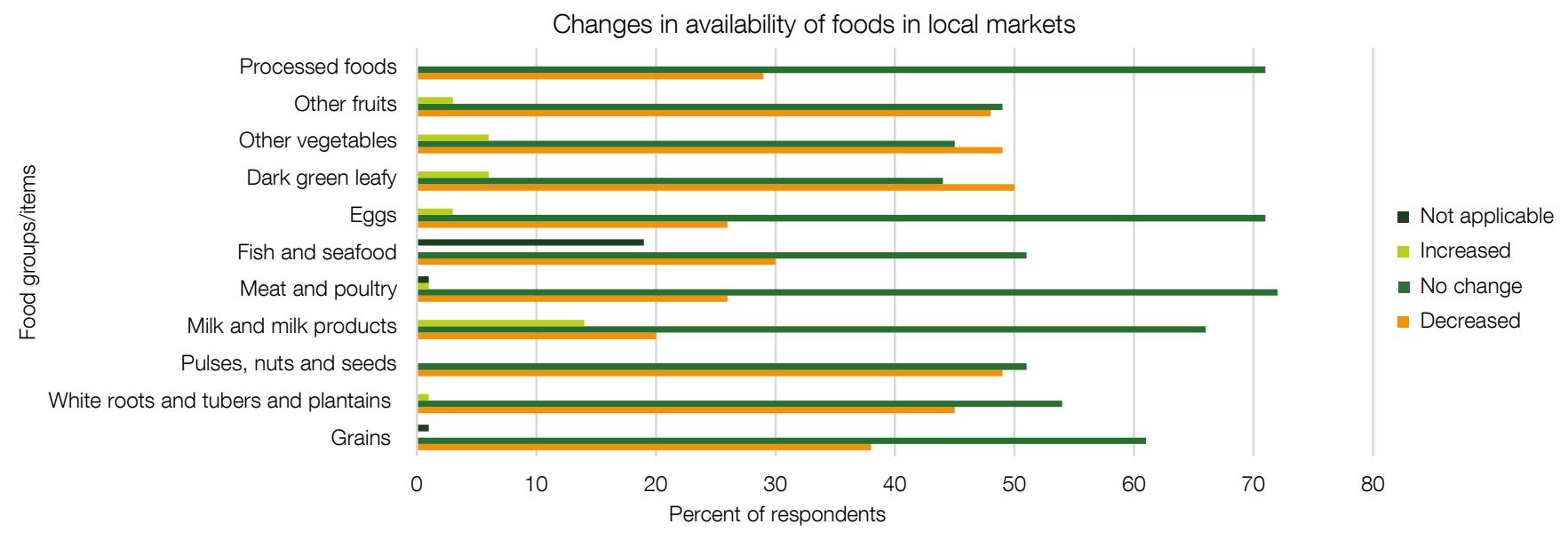

\section{Responses to the threat of COVID-19}

Like other countries around the world, Kenya has established and continues to take a broad range of measures and provide policy guidelines to manage and control the spread of COVID-19 and its potential effects.

The measures include restrictions on population movements and social gatherings; restrictions on economic activities; health-specific measures; social protection interventions; fiscal policies; monetary and financial policies; farm fiscal interventions; and trade policies.
In addition to observing the government-established guidelines for prevention of the spread of COVID-19, all respondents reported that they were observing simple health guidelines, such as washing of hands, wearing face masks and practising social distancing.

Respondents also reported reduced movement within the village (86\%), reduced movement outside the village (96\%) and limited visits by/to relatives (77\%).

Nearly $90 \%$ observed a decrease in the number of traders/ brokers coming to their villages, which implies reduced contact with outsiders. International licence (CC BY-NC-ND), which permits use and distribution in any medium, provided the original authors and source are credited, the work is not used for commercial purposes, and no modifications or adaptations are made.

If you use the work, we ask that you reference the APRA website (www.future-agricultures.org/apra/) and send a copy of the work or a link to its use online to the following address for our archive: APRA, Future Agricultures, University of Sussex, Brighton BN1 9RE, UK (apra@ids.ac.uk)

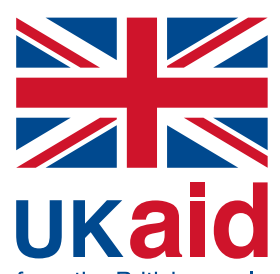

This report is funded with UK aid from the UK government (Foreign, Commonwealth \& Development Office - FCDO, formerly DFID). The opinions are the authors' and do not necessarily reflect the views or policies of IDS or the UK government. 